\title{
Constituting the workplace curriculum
}

\author{
Stephen Billett \\ Faculty of Education \\ Griffith University, Australia
}

Billett, S (in press 2005) Constituting the workplace curriculum, Journal of Curriculum Studies
37 (3)

\begin{abstract}
This paper advances some bases for a workplace curriculum. These are premised on conceptions of curriculum as intents directed to individuals' progression towards full and effective workplace performance, yet whose enactment is shaped by workplace factors and is ultimately experienced by workers as learners. So whether the intentions will be realised is likely premised on the support (affordances) for their enactment by interests within the workplace. These interests are directed towards the workplace's continuity including individuals and their affiliates standing in the workplace. Workplace affordances, like those in educational institutions, emphasise the role that the norms and social practices that comprise workplaces play in regulating individuals' engagement in and learning through work. The degree by which these affordances invite, structure, support and guide participation and are likely to engage workers in the kinds of thinking, acting and learning required for effective workplace performance is important for developing effective vocational practice. Yet, the degree of consonance between individuals' interests and these workplace affordances will ultimately shape individuals' experience of and engagement in learning. So the conception of an ideal curriculum directed towards full participation is subject to the affordances of the interests of managers, co-workers and factors affecting production, as well as the intentionalities of worker-learners themselves. These concepts may well provide ways of thinking about curriculum more broadly as participatory practices comprising the interactions between the agency and continuities of both the social practice (e.g. educational institutions, workplaces etc) and individuals who participate in and learn through their engagement in these practices.
\end{abstract}

\section{Constituting a workplace curriculum}

There is an urgent need for workplace curriculum practices and principles to be identified, elaborated and evaluated. This need arises partially from the acknowledgement of the crucial role that workplaces play in individuals' initial learning and further development of vocational knowledge throughout their working lives. Without the identification, conceptualisation and acknowledgement of a workplace curriculum, workplaces will remain misunderstood, open to easy criticism and de-legitimised as learning spaces. Much, if not most, of the learning throughout working lives will probably be acquired, refined and developed further in workplace settings as individuals deploy and extend their knowledge through their everyday work activities. Consequently, workplaces need to be conceptualised more clearly as learning environments through identifying their characteristics and qualities (i.e. their capacities to assist developing vocational practice) and considering how their contributions can be best organised to assist the 
learning required for work. In appraising their capacity to develop vocational practice as a curriculum outcome or goal, it is necessary to consider what learning individuals intend as much as their workplace or employer. Any consideration of curriculum, whether for educational institutions, workplaces or elsewhere, will necessarily be required to confront the relations between those who organise and enact learning experiences, and the goals and needs of those who are to be subject to them. Therefore, it is important to identify and elaborate some bases for promoting, organising and acknowledging ongoing learning throughout working lives. For many workers, there is often no viable alternative, because courses or programs are not available or are inaccessible. Therefore, to fail to support their learning at work is to further disadvantage workers who are denied access to the educational programs and certification available to and enjoyed by others.

This paper attempts to address part of this need through identifying and discussing factors that shape the organisation and enactment of a workplace curriculum. Three conceptions of curriculum often used to understand practices in educational institutions are exercised for this purpose. These are: the 'intended curriculum' - what is intended to occur; the 'enacted curriculum' - what actually happens when the curriculum is enacted; and the 'experienced curriculum' - what learners experience, construe and learn as a result of its enactment. For some, the 'experienced curriculum' is the only reasonable definition of curriculum.

Although, this paper utilises and is informed by curriculum concepts and theorising premised on activities in educational institutions, it is not intended that the workplace curriculum be hostage to constructs and practices arising from those institutions. What is advanced here as bases for a workplace curriculum have geneses that both predates and extends beyond efforts to organise learning in educational institutions. Moreover, it is proposed that these bases are not reserved for what happens in workplaces or educational institutions. Rather, they can be applied and have meaning in social practices wherever participation in and the remaking of these practices of all kinds occurs. Dewey (1916), in accepting the broader view, proposed that curriculum is grounded in the activity and interrelationships of persons as an interaction between the learner and the world. He viewed experiences as the interplay of activity, being acted upon, reflected upon and experienced. These precepts are not confined to what occurs in education institutions. They highlight the need to conceptualise curriculum as a set experiences whose purposes and interactions are constituted more broadly and in ways that reflect the enactment of interest, power and influence in social settings beyond education institutions and even workplaces. Whether referring to what is intended to be learnt in schools or workplaces, and in what ways (how teachers or co-workers decide what they will teach or guide and in what ways) or how students or workers elect to participate in and learn from what is enacted, these are both shaped by the exercise of power and influence and their contestation those who are subject to them. So, just as schools in the United Kingdom (Young, 1971), America (Bowles and Gintis, 1976) and Australia (Connell, Ashenden, Kesseler, and Dowsett, 1982) have demonstrated a capacity to reproduce unequal outcomes, so too have workplaces (Billett, 2001). Because of this, it is quite erroneous to refer to workplaces as informal learning environments (Billett, 2002a). The structuring of workplace learning experiences are shaped by structural factors associated with work practices. These regulate and are reproduced by the division of labour and the distribution of opportunities for participation in work and learning about it. This structuring, and its contestation, is no more evident than in accessing or learning about work tasks that are highly valued or remunerated. This structuring underpins the need to identify ways of intervening in workplaces to assist in the equitable distribution of learning experiences.

For the purposes of identifying bases of a workplace curriculum, these conceptions of curriculum and sentiments about their enactment are used to discuss three questions: (i) How should a workplace curriculum be best organised? (ii) What factors likely to influence its enactment? (iii) How will workers experience and learn from engagement in workplaces? They 
are framed by larger questions about how individuals participate in and learn through engagement in social practices per se.

In preview, the 'intended' workplace curriculum takes as its starting point an anthropological conception of curriculum as participation in social practice: Lave's (1990) 'learning curriculum'. This comprises the sequencing of a pathway of activities that leads the worker-learner from novice status to being able to participate effectively in, and potentially transform, the particular social practice (e.g. workplace). Movement along this pathway needs to account for the kinds of knowledge to be learnt, to engage fully - particularly that which cannot be learnt alone or requires practice to secure proficiency. Considerations of the knowledge to be learnt to become an effective and productive practitioner, and how this learning can be best supported, constitute key elements of the ideal 'intended' workplace curriculum. In adapting this concept to contemporary workplace settings, current work organisation and employment practices, as well as the problem of learning knowledge that is hidden or otherwise 'hard-tolearn', need to be elaborated and accommodated.

A central proposition underlying the conceptualisation of a workplace curriculum is that workplaces will invite workers to engage and learn, insofar as that participation serves its goals and/or the interests of those within it. That is, the continuity and/or development of the workplace or affiliates or individuals within it. Therefore, the bases for the enactment of workplace curriculum are likely to be shaped by: (i) particular interests (e.g. affiliations, cliques) in the workplace and their capacity to influence the enactment of the workplace curriculum; and/or (ii) individuals' goals for participation and advancement. For fear of being displaced, existing and more experienced workers may resist the participation and learning of new or other workers. Individuals' gender, race, aspirations or personal affiliations may also shape how their participation and learning is supported through work activities. Management may elect to either support or resist workers' learning because of either the need for those skills or concerns about financial cost or loss of control. However, individuals themselves will ultimately determine how they participate in and learn through what is afforded them, premised on their values, goals and experiences. Hence, both the enactment and experiencing of a workplace curriculum are likely to be contested and negotiated. This negotiation between the social structuring of knowledge and individual agency is commonly acknowledged in many accounts of human cognition and action within psychology (e.g. Valsiner and van der Veer, 2000), sociology (e.g. Giddens, 1984) and philosophy (e.g. Taylor, 1985). Perhaps the ideal workplace curriculum is one in which the goals and interests of the workplace (intents) and those of individuals who participate in it are shared.

In the following sections, conceptions of curriculum as intentions, enactments and experiences are used to elaborate bases for a workplace curriculum. In elaborating these concepts, each one is discussed in terms of its features, contributions and continuities.

\section{Workplace curriculum as intentions}

In conceptualising a workplace curriculum, some existing curriculum concepts can be applied directly or analogously to identify bases for proposing what might be the 'ideal' intended curriculum - that which is supposed to be enacted. The issue of the ideal raises the question about from what perspective is it ideal. It is unusual for educators or students to initiate educational institutions or programs (Skilbeck, 1984). It is often powerful interests that organise education as a means of regulating their continuity (Bernstein 1996). As the intended curriculum (e.g. syllabus documents, curriculum standards and frameworks) in educational systems are typically regulated by powerful and external forces (e.g. government, religious orders, industry, pressure groups), so to is the intended workplace curriculum. Many definitions of curriculum refer explicitly to being primarily about achieving the school's goals -- that is its continuity. In this way, the educational institutions' programs and goals will reflect their particular niche in the educational sector (e.g. securing academic achievement, providing vocational preparation, enhancing sports proficiency, accessing higher education, supporting particular religious or 
educational values etc). An educational institution that makes claim for high academic achievement is unlikely to champion its remedial or vocational programs. The emphasis of learning experiences and acknowledgement of student achievement will be directed towards those goals and ultimately, its continuity.

Here, an approach to an intended workplace curriculum is focused on how learners would acquire the knowledge (e.g. concepts, procedures, dispositions) to perform functionally and effectively in their workplace role and develop further their potential through workplace experiences. The latter concern is important. As Dewey (1916) notes, there is no greater waste than individuals not being able to exercise their full potential within their vocational practice. A goal for vocational curriculum is to assist individuals identify and realise their full vocational potential. According to Lave (1990), the curriculum for the workplaces she observed comprised pathways of activities in which the novice workers participated as learners. This participation ultimately led to effective performance with tasks that had a high error cost. Their employers, master tailors to whom they were apprenticed and in whose workshop they lived throughout the duration of their indenture, regulated the sequencing and pace of the individual apprentices' movement through these activities. These pathways commenced with engagement in tasks of low accountability and standing (i.e. low error cost to the employer if mistakes were made) through to tasks of higher accountability (i.e. high error costs) and greater standing in workplace. Participation in and progress along these pathways engaged learners in the kinds of practicebased thinking and acting that leads to competence with these practices (Lave, 1993). The structuring of these pathways acknowledged that some kinds of learning are difficult and require the prior development of initial skills and strategies to make accessible the goals for workplace performance. In considering the requirements of contemporary work, particularly for knowledge that is hard-to-learn because it is difficult to observe, complexity of those requirements may need be elaborated for the learner (Billett, 2001). Here, guidance of more experienced co-workers will probably be needed to support progress along that pathway of learning. It is noteworthy that the pathway constituting the curriculum that Lave (1990) identified is analogous to the original meaning of the term curriculum: currere - 'the track to be run', the course of learning (Marsh and Willis, 1995). From an anthropological account of learning, through participation in practice, the course of learning is not presented as a set of subjects to be undertaken and passed as in educational institutions. Instead, there is a sequence of tasks to be successfully learnt and practiced on the way to learning to perform more complex and demanding tasks that are central to the continuity and survival of the community (Pelissier, 1991). So, the sequencing of workplace activities that workers progress along is premised on securing the continuity of the work practice (i.e. the enterprises' goals, or those of cliques and affiliates in workplaces) through participants' learning. These considerations likely take two forms: firstly, addressing a need to develop the kinds of skills that the enterprise requires to function effectively to survive and prosper; and secondly, developing these skills in ways that do not jeopardise the enterprise's survival.

Although not stated in the form of a syllabus, these pathways as curriculum have purposes (i.e. intents). They function in similar ways to a syllabus: setting out the activities, goals to be achieved and means by which progress and attainment can be secured. As foreshadowed, in Lave's (1990) study, tailors' apprentices learnt by participating in workplace activities sequenced to provide engagement in tasks of increasing accountability and complexity. This pathway of participation incrementally provides access to learning the capacities required for work. The apprentices' initial activities were structured to provide access to the overall workplace goals and then the performance requirements of particular tasks. Initially, they finished and ironed completed garments. Engagement in these activities provided opportunities to understand work goals, including the standard of finish demanded for garments, and the shape of garment components. It presented the apprentices with observable and explicit goals for their performance. Next, the apprentices learnt specific procedures for constructing garments (e.g. sewing garment seams, waistbands, hems). The pathway of learning experiences was structured 
by engagement in tasks of increasing accountability. This comprised initially engaging in tasks where mistakes could be tolerated (e.g. making children's and undergarments) to those where mistakes have significant consequences (e.g. ceremonial garments). The requirements for performance and indirect guidance through observation were made accessible and learnable through the apprentices' ongoing participation in everyday work activities. In this way, the workplace's norms and practices provided a curriculum through structuring the apprentices' activities, thereby shaping their learning through experiences that were intentionally structured by pedagogical purposes.

These propositions are well supported. Cognitive (Anderson, 1993; Shuell, 1990) and sociocultural (e.g. (Rogoff, 1995) constructivist psychological perspectives similarly link engagement in goal-directed activities with learning, with the latter emphasizing the interpsychological processes - those between individuals and social sources that occur through engagement in socially shaped activities and with support from social partners, such as might occur in workplaces. Similarly, engagement in everyday workplace activities is held to reinforce, refine or extend individuals' knowledge (Rogoff and Lave, 1984). Lave (1993) concludes that whenever you examine practice you identify learning, making the link between engaging in social practices, such as work, and the structuring of learning. The cognitive view suggests that the novelty or routineness of the work activities for individuals shapes opportunities for new learning, and refining and honing what has been learnt (Anderson, 1982; Van Lehn, 1998). Therefore, more than an end in itself, engagement in work activities incites change in individuals' capacities: learning. This learning is assisted by support and guidance when engaging in new tasks and their refinement (Collins, Brown and Newman, 1989). The ordering of experiences and engaging learners in tasks in workplace settings are often analogous to pedagogic practices within educational settings. Instructional schemes such as cognitive apprenticeships (Collins et al., 1989), reciprocal teaching (Palinscar and Brown, 1984) and the half-worked problems that are used to reduce cognitive load (Renkle, 2002) are comparable to such processes. Moreover, the focus on learning rather than teaching has been widely adopted in models of instruction premised on constructivist principles (Vosniadou, Ioannides, Dimitrakopoulou and Papademetriou, 2002). Discovery and peer learning processes (Fischer, Bruhn, Gräsel and Mandl, 2002) currently being trialled and investigated in school settings are all highly analogous to the kinds of pedagogical practices identified in anthropological accounts of the intentional organization of learning by communities (Pelissier, 1991), and can be categorized under the motif of participation

In other work and more contemporary settings, similar curriculum pathways of learning and their pedagogic properties have been identified. In hairdressing salons, the tasks apprentices engage in and their progress through these hairdressing tasks are regulated by the salon's approach to hairdressing (Billett, 2001). In one salon, where clients are attended to by a number of hairdressers, the apprentices first engage in 'tea and tidy', providing hot beverages for clients and keeping the salon clean and tidy. These tasks are necessary components in understanding and performing as a hairdresser. Through these activities, apprentices learn about and practice procedures for determining client needs, hygiene and maintaining cleanliness. For instance, identifying clients' needs and providing them with tea or coffee assist in building the apprentices' capacities and confidence to negotiate with clients. Next, apprentices engage in washing clients' hair and later rinsing the chemicals used to shape and/or color clients' hair. Engagement in these tasks develops further the apprentices' capacities to communicate and negotiate with clients. Throughout, the apprentices learn inter-psychologically through direct interpersonal interactions with experienced hairdressers and more indirect kinds of participation (i.e. observation and listening) to understand and practice salient aspects of each task (e.g. the importance of removing all the chemicals), and each task's place in and significance to the hairdressing process. Later, apprentices work with experienced hairdressers in placing rods and curlers in clients' hair. Then, before being permitted to cut women's hair, they commence cutting men's hair. This is held to be less difficult and of lower accountability (i.e. lower error cost) than cutting women's hair. The 
apprentices continue on this path of activities and engagement in practice until they can style hair independently. So there is a track providing incrementally more demanding tasks (i.e. new learning), and then practice (i.e. refinement) in those tasks that assist in the development of the apprentices' workplace practice. This track of activities constitutes a central principle of a workplace curriculum, and one founded on maintaining the workplace's viability. This principle may prove to be broadly applicable across different kinds of work.

However, because the work requirements are not uniform, curriculum pathways may be quite particular to each workplace, even across the same occupational practice. For instance, in another salon, there is a different division of labor, with each hairdresser undertaking the entire hairdressing task. There, the apprentice is required to learn to cut and color independently far earlier than in the first salon. The structuring of activities in the second salon includes gaining competence with procedures that permit early independent practice (Billett, 2001). Therefore, in the same vocational practice, the particular workplace's goals and practices will shape the structuring and sequencing of the activities that constitute the kinds of tasks to be undertaken and to what standard: the intended workplace curriculum. The two salons have distinct hairdressing goals and practices, and different bases for their continuity. These differences reinforce the localized factors that constitute a particular workplace curriculum. The need to acknowledge and understand localized requirements is well recognized within curriculum practices for educational settings. The School Based Curriculum Development movement in the 1980s had its genesis in concerns about meeting the needs of specific school settings through mechanisms that were more sensitive and responsive to localized need than top-down curriculum provisions (Skilbeck, 1984).

These examples also highlight the pedagogic qualities that can constitute the intended workplace curriculum. These include assisting learners to understand the requirements for effective work: the curriculum goals. Like those stated in syllabuses, these goals may need to be made explicit and be the subject of intentional guided activities in the workplace, because what constitutes effective work practice is often hidden or hard-to-learn. Novice police officers may not understand the kinds of detail required at a crime scene or an arrest until they are questioned in court many months later; coal miners may be quite unaware of the consequences of the amount of foreign matter in what they extract from a mine site unless they are made aware of the processes at the coal washing and grading facilities (Billett, 2001). In one warehouse, workers who pack and load pallets onto delivery trucks were sent with the trucks to understand the requirements for the pallets to remain intact during their transportation and unloading at the stores. Without this experience, these workers would be less likely to understand the requirements for packing the pallets. It may also be necessary to intentionally support hard-tolearn knowledge in the workplace. That learning may be demanding because the task is complicated, multi-faceted, difficult to manage, or hard to access and learn about. In these circumstances, close guidance by a more experienced co-worker may be required to support this learning. However, this provision of guidance needs to be preceded by identifying what tasks are hard-to-learn and why they are hard-to-learn. The evidence suggests that it is worth securing more than one perspective on what comprises hard-to-learn tasks. When both experienced and relative novices were asked to rate the difficulty of a range of work tasks, there were differences in the views between the two groups (Billett and Boud, 2001), suggesting that more experienced workers may not always be the best judges of what comprises difficult workplace tasks for learners.

In summary, an ideal intended workplace curriculum comprises the identification and sequencing of work activities that represent the 'course to be run' - that lead to full participation in the particular work practice. This process is likely to be shaped by the requirements of the workplace, including how work is organized and labor divided, as well as the goals that are to be realized through permitting individuals to learn more about that practice. They may commence with tasks of low accountability or error cost to the particular interests that organized their sequencing. Although not written down, the sequencing of workplace tasks may perform a 
syllabuses' role. There are pedagogical properties in the sequencing of engagement in work activities. However, these activities may need to be structured to assist novices learn about the requirements for effective practices -- the goals they have to achieve -- and provide bases for monitoring progress and making judgments about the attainment of skills. The tasks that are hardto-learn need identifying and support provided for learning those tasks. It is here that intentional instructional strategies, such as modeling, guiding, using questions and diagrams as well as the opportunity to rehearse and repeat these activities, need to be deployed as part of everyday work activity. Together, these represent the 'ideal intended workplace curriculum' - that is 'what should be' - in taking an individual to being an effective worker deployed to their full potential and in ways that reflect their interest. So, while it is easy to classify workplace learning experiences as technicist, they may also hold the promise of being emancipatory in so far as they can allow individuals to achieve their desired direction or goals. This is what Dewey (1916) proposed as being a key educational goal.

Therefore, the focus of the intended curriculum in addressing the intents and requirements of the particular social practice is not restricted to educational institutions or workplaces. It is a more general curriculum concern. Yet, it is how the intended curriculum is enacted -what is- that ultimately shapes what learners experience.

\section{The enacted workplace curriculum}

As with educational institutions, conceptions of a workplace curriculum need to go beyond what is intended. There is also a need to understand how factors associated with the enactment of those learning experiences shape what workers experience and engage with. Within educational practice, it has been long understood that no amount of external control or mandation can ensure what is intended will be enacted with fidelity (Hall and Loucks, 1977). The decisions that teachers make in enacting the curriculum in educational institutions are based upon their experience, values, preferences and competence. So their interpretation of a syllabus, how best its goals might be achieved, and the selection of possible learning experiences are not able to be prespecified. Moreover, the contributions of teachers in augmenting what is presented in curriculum documents can provide rich experiences, referred to as the 'effective' curriculum (Skilbeck, 1984). For instance, in a study of how vocational educators had assisted developing students' vocational knowledge that transferred from the college setting to the workplace, students frequently reported the importance of stories and examples provided by teachers (Billett and Beven, 1999). Moreover, beyond the teachers' contributions are the kinds of opportunities, interactions, resources and infrastructure that are available to provide appropriate learning experiences. Even with the best and most faithful intent, learners' experiences may be constrained by these factors, what is referred to as the 'available' curriculum. So, for instance, nurses being prepared in university health faculties may not be able to access the depth and array of nursing experiences that hospital-based nurse education provides.

In a similar way, learning experiences enacted in workplaces may vary from what was intended or is ideal. Those factors determining the 'enacted' workplace curriculum include the concerns and continuities of those individuals who organise activities in the workplace. The intended learning curriculum may well reflect a desired track of experiences. Yet, it is others in the workplace who regulate learners' access to activities and interactions, and provide the support that regulates learners' progression. Decisions about and support for learners' access to these experiences will most likely come from three sources: (i) employers/managers; (ii) co-workers; and (iii) service and production factors.

Firstly, employers may either deliberately support or restrict workers' participation in and learning about work activities dependent upon particular purposes. If there is a need for a particular task to be performed, workers might be actively supported and encouraged to learn that task, because it is in the enterprise's interest. With changes in production or in legislated requirements, even enterprises that are normally reluctant to expend funds on training will 
support that learning (Billett, 2000). Employers might also want to extend the workers' skills to make them more broadly deployable within the workplace or aim to secure a greater sense of attachment to the workplace by employees through a process of developing their skills and understanding about the particular requirements of the workplace. Some evidence suggests that this kind of involvement sustains enterprises over time: the securing of their survival and continuity (Rowden, 1995).

However, conversely, if employers or managers perceive threats to their continuity and control of the enterprise arising from the development of workers' skills, they may act to restrict that development. Because of such fears, Danford (1998) reports that management dismantled the self-managed teams that were securing productivity improvement. As Braverman (1974) held, management may subordinate efficiency and productivity to maintaining the control of the means of production. In each workplace there will be a limit on the number of highly remunerated workers it can sustain. Therefore, to remain viable or secure a desired level of profitability, employers may work to limit the amount of skill development that occurs, particularly when that development is structurally rewarded through higher levels of remuneration. In a study of coal workers' mine site learning, management were concerned about workplace arrangements that linked levels of remuneration to the acquisition of training modules, when this learning did not lead to productivity enhancements commensurate with the increased wages costs (Billett, 2001). So progress towards full participation may be constrained to avoid the workplace becoming unviable or operating with reduced profit. Moreover, it may be not be feasible to provide the range or quantum of learning opportunities that workers desire. The required level of practice on equipment or engagement in tasks may simply be unavailable through a lack of opportunity. For instance in open cut coalmines, becoming a dragline operator is a prized role. However, there is little worker turnover and few opportunities to practice on a multimillion-dollar piece of equipment that needs to operate productively twenty-four hours a day and seven days a week. So there may be unresolvable conflicts between individuals' desire for skill development and needs for those skills in the workplace: an internal supply and demand problem. Employers or owners are also selective about how they direct their support for learning among their employees (Groot, Hartog and Oosterbeck, 1994). Employers appear unwilling to provide opportunities for learning for part-time or contractual workers (Brunello and Medio, 2001). Lacking workplace support to advance their skills, these contingent workers are doubly disadvantaged. So just as institutional practices of schools may influence who participates in what activities, the actions of owners and managers shape the range of learning opportunities in workplaces.

The second set of influences upon how the workplace affords learning experiences is the beliefs and actions of co-workers. Workplaces are not benign environments. Co-workers may not support other workers' development and progression. The degree of support is likely to be dependent on how this learning and advancement are seen to affect co-workers' interests. For instance, expert workers may be unwilling to assist other workers, if they believe that they may be displaced by those whom they have supported (Lave and Wenger, 1991). In uncertain times, those with skills may be reluctant to share their expertise with other workers, particularly those paid at a lower rate. The interests of workplace affiliations and cliques also regulate who is afforded learning support and in what ways. Full-time workers may restrict the activities of parttime workers (Hughes and Bernhardt, 1999), 'old-timers' restrict those of 'newcomers' (Lave and Wenger, 1991), professional or trade affiliations may work to support their affiliates while marginalising others (Billett, 2001). Then, there are the inevitable workplace factions that serve to regulate the distribution of activities, interactions and judgements about others' performances. Workers' gender (Bierema, 2001), race and language (Hull, 1997) also shape how they are supported in the workplace by management and co-workers. In short, workplaces are contested learning environments in which relations among workers and support for learning are unlikely to be benign, because the learning and development of some workers may threaten others. 
The efforts and support of co-workers is salient for learning through work. In a year-long study of guided learning in three work areas in a workplace that prided itself on learning support for its employees, the support available to learners was largely shaped by the efforts and skills of more experienced co-workers (Billett, 2003). Ultimately, it was the personal qualities and characteristics of co-workers that regulated the support for learning provided in the workplace. In an earlier study, of a manufacturing plant that offered little in the way of support, a co-worker, through his own efforts, was able to provide rich learning experiences to workers who had not previously experienced any support. Where evidence exists of strong support for co-workers' learning, it is often in circumstances where the person providing the support is in some way an affiliate. Senior women public servants or executives form relationships with younger women to advise them on work choices and difficult career decisions to assist their career development (Arnold and Davidson, 1990; Vincent and Seymour, 1994). The support is also likely to be provided where there is no risk to individuals' employment or standing (Dore and Sako, 1989; Hughes and Bernhardt, 1999) or when those assisted will become supporters of their mentor (Allen, Poteet, and Burroughs, 1997). However, even with the most well-intentioned and best efforts of co-workers, there remains the risk that co-workers working alone and without support themselves may be unaware of all the kinds of knowledge that need to be learnt. Worse still, they may guide the development of practices that are short-term and habits that may even be dangerous. So, whether the workers' learning experiences and progression are constrained or promoted by management practices or co-workers, they are usually shaped by particular sets of interests.

The third source of influences are factors beyond employers and co-workers' influence which may also regulate the kind of learning experiences that are afforded individual workers or cohorts of workers. There are demarcations that arise from societal expectations. Dental assistants are expected only to assist; nurses nurse, not diagnose etc. Also, the level of production or service can influence the kinds of opportunities that are made available. For instance, the reduced demand for a product saw one team of workers lose the opportunity for further skill development and another team lose access to the training funds that were used to support training relief in their work area (Billett and Boud, 2001). However, quite the opposite can occur when there is a labour shortage. For instance, in many parts of rural Australia, nurses are required to perform medical tasks that would be only undertaken by doctors in provincial and metropolitan centres. The shortage of doctors has led to a demand for nurses to provide a wider range of services and be trained to conduct those services safely. Then, as noted above, there is the simple availability of plant and equipment. If such infrastructure is not available, it may be difficult to provide the kind of practice that is often so important in developing skilful performance: the available curriculum would be weak.

So, just as with educational institutions, there can be no guarantee that the 'intended' workplace curriculum will be realisable. The actions of individuals and co-workers in enacting a workplace curriculum are directed by particular interests and focused on particular continuities (e.g. the workplace, their personal or affiliate's continuities). These may serve to either support or inhibit access to the kinds of activities and interactions required to assist individuals' development in the workplace. The concern for organisation of the enacted workplace curriculum is to attempt to find ways to improve and enrich the workplace learning experiences, through guidance and the ordering of experiences in order to secure fair and positive outcomes for all workplace learners (Billett, 2001). This can include guided participation in activities and the provision of direct guidance by more expert co-workers.

However, while being highly influential, whatever is enacted is not the sum of a workplace curriculum. Ultimately, learners determine whether what was enacted constitutes worthwhile learning experiences, and are worth engaging with, and in what ways. 


\section{The workplace curriculum as experienced by workers}

Beyond the experiences that are intended and enacted, learners will interpret and construct meaning in ways that may or may not be consistent with the intentions of those who enacted those experiences. In educational settings, for instance, tasks set for students as problem-solving activities may become a basis for guessing or trial and error (Posner, 1982), or a competition to finish first, to please the teacher or to 'look smart' (Dweck and Elliott, 1983) or premised on whether learners have the confidence to proceed with the task as intended (Belenky, Clinchy, Goldberger, and Tarule, 1986). Similarly, there can be no guarantee that individuals participating in workplace activities will learn what was intended or has been enacted. Individuals will likely decide how they engage with what the particular social practice affords them (Goodnow, 1990). The cultural psychologist Valsiner (1998) proposes "most of human development takes place through active ignoring and neutralisation of most of social suggestions to which the person is subjected in everyday life" (p. 393). This is essential to buffer individuals' personality against the demands of constant social suggestions. This suggests that the regulatory practices (Bernstein 1996) enacted in educational institutions and workplaces alike are subject to individual agency and intentionality.

The significance and implications of this exercise of individual agency go beyond how individuals behave or perform in education institutions or workplaces. Most salient is the strong association between engagement or participation in activities and learning - activity structures cognition (Rogoff and Lave, 1984). The degree by which individuals elect to engage in a particular task or interaction is likely to have cognitive consequences - that is, for the kind of change or learning that occurs (Newell and Simon, 1972). Learning is highly effortful, particularly in learning new knowledge that requires some restructuring of existing understandings and practices (Van Lehn, 1998). Therefore, the degree of self-directed interest and engagement that individuals enact will probably have specific implications for the learning (Perkins, Jay, and Tishman, 1993; Tobias, 1994). As foreshadowed, individuals participate and learn in ways directed towards the continuity of their interests and goals (Somerville, 2002). How they exercise their agency: their agentic action is influenced by their goals, subjectivities and identities. How their agentic action is directed will have consequences for their learning. In one worksite, a production worker went to extraordinary lengths to understand the work of fitters (Billett, 2001). The source of his agentic action was that he was a fitter by trade and wanted to be employed as a fitter in this workplace. His goal was to participate more fully than existing staffing levels currently permitted him. Similarly, a grief counsellor by force of personality and persistence was able to reshape the counselling practice in his workplace in ways aligned to his particular beliefs about counselling. This action reshaped the operation of the workplace in ways that had impact upon other workers (Billett, Barker, and Hernon-Tinning, in press). The important point is that individuals exercise agency in how they participate in the workplace, including potentially transforming the work practice, and what they learn through their participation.

Drawing upon Leontyev (1981), Wertsch's (1998) uses the concepts of mastery and appropriation is helpful in considering how workers construe experience and elect to learn through work. Mastery is viewed as being a superficial form of learning that individuals will engage in when subject to socially-derived demands and requirements. However, they may not believe in or even understand the purpose of this knowledge, but can reproduce it for required performance. Appropriation, on the other hand, is learning that is more wholeheartedly adopted and engaged in by learners. However, the individual construction that sits behind both mastery and appropriation can be problematic. If an individual does not appreciate the importance of a particular practice (e.g. safe work practices), they may only master it. Similarly, workers may well appropriate dangerous work habits or shortcuts.

In this way, individuals also decide what constitutes workplace affordances. This may occur in ways that are counter to the best intentions or most invitational qualities of the 
workplace. For instance, one worker refused to participate as a workplace mentor because he could identify no personal advantage from expending effort in this way. Another rejected the support and interactions provided by his new workplace, because he believed his expertise to be superior to that of his assigned mentor and that his standards of skill was higher than that practised in the workplace - so he had nothing to learn from them (Billett, 2001). In essence, both these workers rejected opportunities and support, respectively, afforded by the workplace, because they concluded, rightly or wrongly, that the kind of engagement was not in their interests or designated career trajectory. In highly contested work environments, the workers' construal of affordance may be premised on suspicion and distrust. At one coalmine, the management's offer of additional safety training was firmly rejected by the coalminers (Billett, 2001). Such was the distrust in the workplace that these miners viewed the safety training as a ploy to further transfer the responsibility for mine site safety to the workers. That is, they viewed this offer of training as being most uninviting and complicit in eroding the traditional responsibility of mine site management for workplace safety. Darrah's (1996) study of a computer manufacturing plant in California demonstrated how workers of Vietnamese heritage resisted teamwork because it countered their Confucian Heritage Cultural beliefs about being judged as an individual not as a team member. These workers believe the social system they despised and had fled from (i.e. communism) had followed them to Silicone Valley. Even if forced to work under team-based arrangements, these workers would likely only master the concepts about teamwork that their employer intended.

Even when action by workers is precipitated by the threat of redundancy, the kind of learning that occurs may be premised more on survival, placating managers or supervisors than learning richly about work performance (Billett, 2002b). The important point here is that learning experiences are something construed and judged by individuals through their interactions with the workplace. Ultimately, they will make judgments about what constitutes workplace affordances and how they might engage with what is afforded. So, conceptions of a workplace curriculum, just as that for education institutions has to include the idea that individuals are not passive recipients of knowledge. They decide what they make their own (Leontyev, 1981).

Therefore, in considering the workplace curriculum as something to be experienced, concerns about continuity arise in the form of individuals' goals, identities and subjectivities. This directs how they decide to participate in and learn from the experiences they encounter in the workplace and elect to exercise their agentic action. Moreover, it emphasises that finding ways of securing individual's interests and identities is likely to be central to the task of engaging them in appropriating the kinds of learning that are important both to themselves and the workplace. This is not always an easy goal. A marriage between the two sets of continuities -- the workplace's and the individual's -- is perhaps the ideal for the workplace curriculum. An information technology consultant to five primary schools achieved something of his corporate aspirations when he was promoted from fixing up student and teacher computer problems to taking care of the new computerised administrative system (Billett, Barker and Hernon-Tinning, in press). This made him indispensable to the schools' principals, whose continuity (e.g. performance appraisal) was associated with implementing the administrative system. The teachers, who were left to fend for themselves, were less well served. Similarly, a union organiser was able to realise her concerns about professional practice and social justice through working with the trade union. Also, the grief counsellor was able to transform the work practice to be consonant with his personal beliefs and goals. In these instances, the continuity of both the workplaces and individual workers mutually reinforced through participation in work. So, as with deliberations about curriculum and learning experiences in education institutions, the key element of the workplace curriculum is the relationship between the goals and trajectory of the workplace (and how this is expressed in its affordances of opportunities and interactions) and those of individuals who participate in and learn through their engagement in the workplace. 


\section{A curriculum for the workplace and beyond}

In this paper, some bases and prospects for a workplace curriculum have been advanced and partially elaborated. They may well contribute to broaden the debate about curriculum more generally, and that within educational institutions. It is proposed that an ideal 'intended' curriculum comprises pathways towards full participation within a social practice as a learning outcome and the support for learning required to progress along these pathways. In its ideal form, the needs of both the individual and the social practice (workplace) should be addressed. However, the degree by which these intentions can be realised is likely premised on the support for its enactment by interests within the social practice of the workplace. The exercise of these interests is directed towards the continuity of the social practice and those individuals, affiliation and interests that operate within it. Together, the concepts of the affordances of the social practice and individual engagement emphasise the significant role that the social practice's norms and regulations play in individuals' engagement in and learning. Practices that invite, structure, support and guide participation are likely to engage workers in the kinds of thinking, acting and learning that are important for effective vocational practice. Moreover, the degree of consonance between individuals' interests and what the workplace affords will be salient in shaping individuals' engagement in the kind of learning which they desire and in ways consistent with increasing the quality of their learning experience (Dewey, 1938).

These tentative bases for a workplace curriculum are founded in empirical work and consistent with many curriculum concepts and practices used in appraisals of learning experiences in education institutions. They may provide a useful way of understanding how the purposes of social practices, such workplaces and educational institutions, as well as community organisations and even perhaps families, aim to reproduce themselves and how such processes are complicated by circumstances in which different interests, power relationships and influences are embedded and enacted. Moreover, even powerful forms of social pressure are not immune from the exercise of human agency. Individuals' agentic actions will likely interpret and construe meaning in ways that are consistent with their own personal goals and trajectories (Valsiner, 1998). So, the deliberations here comprise a base from which to consider curriculum and pedagogic practices across the diverse social settings that constitute contemporary workplaces, where individuals participate in work and engage in learning throughout their working lives. Only in testing these concepts against the requirements of diverse workplace practices and occupational endeavours will their voracity be effectively appraised. Furthermore, the kinds of deliberations here about social practice, workplaces and individuals' agentic action might well assist in extending the concept of curriculum beyond the constraints of its conceptualisation being privileged by what occurs in educational institutions. It may assist understanding how the organisation of learning might be conceptualised for other kinds of social practice, albeit in the community organizations, homes or other settings where social practices and individuals interact. In each of these, the concepts advanced here may well provide a means to consider how social practices afford experiences to participate and learn. Yet, it also highlights that beyond the provision of activities and interactions extended by the social practices, that individuals, within reasonable constraints, will elect how they participate and learn. That is, the participatory practices that constitute curriculum in a range of social settings comprise a negotiation between the continuities of both individuals and social practices.

Acknowledgement - I would like to thank the editor for his interest, support and guidance.

\section{References}

Allen, T. M., Poteet, M. L. and Burroughs, S. M. (1997) The mentor's perspective: A qualitative inquiry and future research agenda. Journal of Vocational Behaviour, 51_(1), 70-89. 
Anderson, J. R. (1982) Acquisition of cognitive skill. Psychological Review, 89 (4), 369-406.

Anderson, J. R. (1993) Problem solving and learning. American Psychologist, 48 (1), 35-44.

Arnold, V. and Davidson, M. (1990) Adopt a mentor: the new way ahead for women managers? Women in Management Review, 5 (1), 22-27.

Belenky, M. F., Clinchy, B. M., Goldberger, N. R. and Tarule, J. M. (1986) Women's way of knowing (New York: Basic Books).

Bierema, L. L. (2001) Women, Work, and Learning. In T. Fenwick (ed.), Sociocultural perspectives on learning through work (San Francisco: Jossey Bass/Wiley) 53-62.

Billett, S. (2001) Learning in the workplace: Strategies for effective practice (Sydney: Allen and Unwin).

Billett, S. (2002a) Critiquing workplace learning discourses: Participation and continuity at work. Studies in the Education of Adults, 34 (1), 56-67.

Billett, S. (2002b) Workplace pedagogic practices: Co-participation and learning. British Journal of Educational Studies, 50 (4), 457-481.

Billett, S. (2003) Workplace mentors: Demands and benefits. Journal of Workplace Learning, 15 (3), 105-113.

Billett, S., Barker, M., and Hernon-Tinning. (in press) Participatory practices at work. Pedagogy, Culture and Society, 11 (3),

Billett, S. and Beven, F. (1999) Introduction. In Billett, S., McKavanagh, C., Beven, F., Angus, L., Seddon, T., Gough, J., Hayes, S. and Robertson, I. (1999) The CBT Decade: Teaching for Flexibility and Adaptability (Adelaide: National Centre for Vocational Education Research) 1-14.

Billett, S. and Boud, D. (2001) Participation in and guided engagement at work: Workplace pedagogic practices. Paper presented at the 2nd International Conference on Learning and Work, (Calgary: University of Calgary).

Bowles, S. and Gintis, H. (1976) Schooling in capitalist America (New York: Basic Books).

Braverman, H. (1974) Labour and monopoly capital: The degradation of work in the twentieth century (New York: Monthly Review Press).

Brunello, G. and Medio, A. (2001) An explanation of International Differences in Education and Workplace Training. European Economic Review, 45 (2), 307-322.

Collins, A., Brown, J. S. and Newman, S. E. (1989) Cognitive apprenticeship: Teaching the crafts of reading, writing and mathematics. In L. B. Resnick (ed.), Knowing, Learning and Instruction, essays in honour of Robert Glaser (Hillsdale, $\mathrm{N}$ J: Erlbaum and Associates), 453-494.

Connell, R. W., Ashenden, D. J., Kesseler, S. and Dowsett, G. W. (1982) Making the difference (Sydney: Allen and Unwin).

Danford, A. (1998) Teamworking and labour regulation in the autocomponents industry. Work, Employment and Society, 12 (3), 409-431.

Darrah, C. N. (1996) Learning and Work: An Exploration in Industrial Ethnography (New York: Garland Publishing).

Dewey, J. (1916) Democracy and Education (New York: The Free Press).

Dewey, J. (1938) Experience and Education (New York: McMillan).

Dore, R. P. and Sako, M. (1989) How the Japanese learn to work (London: Routledge).

Dweck, C. S. and Elliott, E. S. (1983) Achievement motivation. In E. M. Hetherington (ed.), Handbook of child psychology (vol. 4) (New York: Wiley), 643-691.

Fischer, F., Bruhn, J., Gräsel, C. and Mandl, H. (2002) Fostering collaborative knowledge construction with visualization tools. Learning and Instruction, 12 (2), 213-232.

Giddens, A. (1984) The Constitution of Society (Cambridge: Polity Press).

Goodnow, J. J. (1990) The socialisation of cognition: what's involved? In J. W. Stigler, R. A. Shweder and G. Herdt (eds.), Cultural Psychology (Cambridge, UK: Cambridge University Press) 259-286. 
Groot, W., Hartog, J. and Oosterbeek, H. (1994) Costs and revenues of investment in EnterpriseRelated Schooling. Oxford Economic Papers, 46 (4), 658-676.

Hall, G. E. and Loucks, S. F. (1977) A developmental model for determining whether the treatment is actually implemented. American Education Research Journal, 14 (3), 263276.

Hughes, K. and Bernhardt, A. (1999) Market segmentation and the restructuring of banking jobs (No. IEE Brief number 24) (New York: Columbia University, Institute on Education and the Economy).

Hull, G. (1997) Preface and Introduction. In G. Hull (ed.), Changing work, Changing workers: Critical perspectives on language, literacy and skills (New York: State University of New York Press) 3-39.

Lave, J. (1990) The culture of acquisition and the practice of understanding. In J. W. Stigler, R. A. Shweder and G. Herdt (eds.), Cultural psychology (Cambridge, UK: Cambridge University Press) 259-286.

Lave, J. (1993) The practice of learning. In S. Chaiklin and J. Lave (eds.), Understanding Practice: Perspectives on Activity and Context (Cambridge, UK: Cambridge University Press) 3-32.

Lave, J. and Wenger, E. (1991) Situated learning - legitimate peripheral participation (Cambridge, UK: Cambridge University Press).

Leontyev, A. N. (1981) Problems of the development of the mind (Moscow: Progress Publishers).

Marsh, C. and Willis, G. (1995) Curriculum: Alternative Approaches, Ongoing Issues (Englewood Cliffs: Merill).

Newell, A. and Simon, H. A. (1972) Human problem solving (Englewood Cliffs, N.J: Prentice Hall).

Palinscar, A. S. and Brown, A. L. (1984) Reciprocal teaching of comprehension-fostering and comprehension-monitoring activities. Cognition and Instruction, 1 (2), 117-175.

Pelissier, C. (1991) The anthropology of teaching and learning. Annual Review of Anthropology, 20, 75-95.

Perkins, D., Jay, E. and Tishman, S. (1993) Beyond abilities: A dispositional theory of thinking. Merrill-Palmer Quarterly, 39 (1), 1-21.

Posner, G. (1982) A cognitive science conception of curriculum and instruction. Journal of Curriculum Studies, 14 (4), 343-351.

Renkle, A. (2002) Worked-out examples: instructional explanations support learning by self explanation. Learning and Instruction, 12 (5), 529-556.

Rogoff, B. (1995) Observing sociocultural activity on three planes: Participatory appropriation, guided participation, apprenticeship. In J. W. Wertsch, A. Alvarez and P. del Rio (eds.), Sociocultural studies of mind (Cambridge, UK: Cambridge University Press) 139-164.

Rogoff, B. and Lave, J. (eds.) (1984) Everyday cognition: Its development in social context (Cambridge, Mass: Harvard University Press).

Rowden, R. (1995) The role of human resources development in successful small to mid-sized manufacturing businesses: A comparative case study. Human Resource Development Quarterly, 6 (4), 335-373.

Shuell, T. J. (1990) Phases of meaningful learning. Review of Educational Research, 60 (4), 531547.

Skilbeck, M. (1984) School based curriculum development (London: Harper and Row).

Somerville, M. (2002) Changing Masculine Work Cultures. Paper presented at the Envisioning practice - Implementing change conference (vol. 3), (Brisbane, Australia: Australian Academic Press) 149-155.

Taylor, C. (1985) Human Agency and Language: Philosophical Papers 1 (Cambridge: Cambridge University Press). 
Tobias, S. (1994) Interest, prior knowledge, and learning. Review of Educational Research, 64 (1), 37-54.

Valsiner, J. and van der Veer, R. (2000) The Social Mind: The construction of an idea (Cambridge, UK: Cambridge University Press).

Van Lehn, V. (1998) Towards a theory of impasse-driven learning. In H. Mandl and A. Lesgold (eds.), Learning issues for intelligent tutoring systems (New York: Springer-Verlag) 3132.

Vincent, A., and Seymour, J. (1994) Mentoring among female executives. Women in Management Review, 9 (7), 15-20.

Vosniadou, S., Ioannides, C., Dimitrakopoulou, A. and Papademetriou, E. (2002) Designing learning environments to promote conceptual change in science. Learning and Instruction, 11 (4-5), 381-419.

Wertsch, J. V. (1998) Mind as Action (New York: Oxford University Press).

Young, M. F. D. (1971) Knowledge and control: New Directions in the Sociology of Education (London: Collier McMillan).

Stephen Billett is an Associate Professor of Adult and Vocational Education, Faculty of Education, Griffith University, Nathan, 4111, Queensland, Australia; email :

s.billett@griffth.edu.au His research interests centre on learning through and for work which he investigates using sociocultural and related disciplinary perspectives. 